\title{
Chair Perceptions of Trust between Mentor and Mentee in Online Doctoral Dissertation Mentoring
}

\author{
Linnea L. Rademaker, Jennifer O’Connor Duffy, Elizabeth Wetzler, and Helen Zaikina-Montgomery
}

\author{
Northcentral University
}

\begin{abstract}
We explored online dissertation chairs' perceptions of trust in the mentor-mentee relationship, as trust was identified as a crucial factor in the success of doctoral students. Through the implementation of a multiple-case study, and a qualitative, online questionnaire, and through qualitative data analysis, we discovered 16 chairs' perceptions of trust and that student vulnerability is an important part of the relationship that chairs consistently work to alleviate. Findings point to the importance for chairs to establish trust through feedback, consistency, and personal connections with students. Second, chairs perceived student vulnerability to include both students' discussion of their academic skills (or lack thereof) and their willingness to share personal information. Chairs were very resourceful in enacting strategies to alleviate all types of student vulnerability, including recognizing student strengths and pointing to the positives of vulnerability and by offering scholarly resources for students to develop their academic strengths.
\end{abstract}

\section{Introduction}

Trust is an essential component in high-stakes relationships (Hunt, Brimble, \& Freudenberg, 2011). Tzafrir and Dolan (2004) defined trust as a multifaceted construct comprised of harmony, reliability, and concern. Trust in mentor-mentee relationships has been researched in numerous business settings, including client-planner relationships in financial planning (Hunt et al., 2011), human resource practices and employees' perceptions of quality of service within the healthcare setting (Tzafrir \& Gur, 
2007), manager-employee relationships (Krot \& Lewicka, 2012), and executives participating in a formal mentoring program (Leck \& Orser, 2013).

Within academia, trust in mentoring relationships has been studied in the context of face-to-face relationships (Eller, Lev, \& Feurer, 2013; Erdem \& Aytemur, 2008; Harding-DeKam, Hamilton, \& Loyd, 2012; Jairam \& Kahl, 2012; Lunsford, 2012) and also in the context of those relationships that are established and maintained online (Crawford, Randolph, \& Yob, 2014; Erwee, Albion, van Rensburg, \& Malan, 2011; Leners \& Sitzman, 2006; Melrose, 2006; Stadtlander \& Giles, 2010). Importantly, de Janasz and Godshalk (2013) found virtual mentoring effects on mentees' learning and satisfaction to be equivalent to face-to-face mentoring. In both contexts the mentor-mentee relationship involves some amount of vulnerability, or exposure to potential harm. Eller, Lev, and Feurer (2013) identified mutual respect and trust as a key component to effective face-to-face mentoring, specifically noting the vulnerability of mentees, and Leners and Sitzman (2006) noted that both mentors and mentees may be vulnerable in the online environment.

Due to rapid enrollment increases in online courses and a surge in offerings of complete degree programs online (Allen \& Seaman, 2012), the question of how mentors establish trust in online relationships is of particular interest. Harding-DeKam, Hamilton, and Loyd (2012) suggested that the responsibility for establishing trust resides with the mentor, yet how mentors work to establish this trust is unclear. Our focus in this study was on how mentors foster trust with online doctoral students who are in the dissertation phase of their programs. We used the following research questions to guide our development and implementation of the study:

Q1. How do online dissertation chairs define and establish trust with their students?

Q2. How do online dissertation chairs perceive student vulnerability and work to alleviate that vulnerability?

\section{Literature Review}

Of the various relationships between mentor and mentee in academia, the one between dissertation mentor and doctoral student is of critical importance for student success. How-to guides and tips from experienced mentors and recent graduates have been the typical means of conveying information about how to manage these interactions and relationships. In the popular book The Compleat Academic: A Career Guide, Darley, Zanna, and Roediger (2003) advised students to become involved in research early on, and the authors offered an entire chapter to professors on mentoring graduate students; they do not offer any advice to either group on how to establish trust. Kritsonis (2008) categorized more than 40 functions of the dissertation advisor, ranging from providing constructive and timely feedback to mentoring students by helping them prepare manuscripts for publication. Despite the dissertation advisor's varied roles, Lunsford (2012) concluded that not all advisors actually mentor their students. Regardless, both mentors and mentees in doctoral programs should be vested in establishing successful relationships.

Of course, research on mentoring relationships in general is not new, and various researchers have found trust to be an important component in a successful mentor-mentee relationship (Eller, Lev, \& Feurer, 2013; Erdem \& Aytemur, 2008; Leck \& Orser, 2013). Effective mentoring of students in an online setting has gained attention recently. Yob and Crawford (2012) called for more research on mentoring online doctoral students specifically, as more online graduate degree programs become available. Several studies have focused on effective mentoring of graduate students in the online environment from the student perspective. For example, Leners and Sitzman (2006) conducted a qualitative study with 36 online graduate nursing students. They asked the students how their instructors 
could best convey caring, which is important for the mentor-mentee relationship and a core value in the nursing profession. Students reported that mentors conveyed caring through a variety of means, such as being empathetic, using an appreciative tone, and providing timely feedback. They also reported that feeling cared for by the e-mentor was a significant motivator. In a study with 228 undergraduate and firstyear graduate students from three universities in the United States, de Janasz and Godshalk (2013) found that perceived similarities in attitudes, values, and goals were associated with higher levels of trust. Students in their study, however, chose their mentors, and the mentors were outside of the universities. We question whether this trend would be replicable in an online environment where departments assign mentors to doctoral students (instead of doctoral students choosing their committees).

Although both Burner (2014) and Trinkner (2014) recently reiterated the importance of trust for guiding online doctoral candidates, few studies actually have looked at how mentors work to establish trust (Yob \& Crawford, 2012). Williams, Sunderman, and Kim (2012) investigated the perspectives of mentors who guided field projects online. Although the course was a capstone course in human resource development, the mentors were external to the institution, and the mentors did not report explicitly on how they established or maintained trust with their mentees. However, Erwee, Albion, van Rensberg, and Malan (2011) interviewed 14 mentors in Australia who were experienced in mentoring doctoral students online. They concluded that keeping the context of both the student and professor in mind is essential for successfully guiding the students. Most recently, Crawford, Randolph, and Yob (2014) developed a quantitative online graduate mentoring scale, although they validated it from the student perspective alone. They divided online graduate mentoring into two domains: academic and psychosocial. Within the academic domain, the attributes associated with effective mentoring included competence, availability, induction of the student into the academic environment, and requiring quality work. The psychosocial attributes included communication and social support. The development and validation of the scale represent some of the first work to try to map out a theoretical framework useful for studying the mentorship of doctoral students in the online context.

Presumably, mentors would report similar variables to be important for effective mentoring of their online graduate students. However, critical information regarding the mentor perspective is missing. Thus, the purpose of this qualitative exploratory study is to investigate the process of establishing trust between dissertation chairs and graduate students from a mentor's perspective in order to provide a better understanding of the necessary attributes. In this way, our study could provide future researchers with added insight useful for validating Crawford, Randolph, and Yob's scale, or other quantitative measurements of trust in the mentor-mentee relationship from a faculty perspective.

\section{Methods}

In order to examine how dissertation chairs who work in an online environment perceive trust within the chair-student relationship, we created and implemented an exploratory, multiple-case study project (Stake, 2005). We decided to use an online, open-ended questionnaire so that we could allow participants to provide broad perspectives on the definition of trust and the ways in which they implement trust activities within their own work with students. The boundaries of the case were dissertation chairs' perceptions of trust, and we categorized each chair's response as a single case in order to account for the differences in how chairs work with their students. We explored chair perceptions by creating an online, anonymous qualitative survey (see Appendix A), which was based upon the following definition of trust: "A willingness to increase one's resource investment in another party, based upon positive expectation, resulting from past, positive mutual interactions” (Tzafrir \& Dolan, 2004, p. 116). We used a qualitative instrument in order to facilitate the exploratory nature of this study in determining how chairs establish trust in one-to-one mentoring of online doctoral students. Based upon the work of Schoorman, Mayer, and Davis (2007), we subdivided the concept of trust into the four categories of reliance, 
altruism/concern for others, vulnerability, and content knowledge. Trust is a key element in a mentormentee relationship, and relationships between doctoral mentors and mentees are essential to mentees' success in a doctoral program (Eller, Lev, \& Feurer, 2013; Erdem \& Aytemur, 2008; Leck \& Orser, 2013). With the growth of online doctoral education, this relationship becomes critical (Parker, Lenhart, \& Moore, 2011).

\section{Participants, Instrument, and Data Collection}

At the time of this study, there were 42 full-time dissertation chairs at this particular university, which offers mostly graduate education, and is completely online. We chose to study dissertation chairs because all authors are also dissertation chairs in an online environment. We felt that our experiences would inform and aid us in our analysis of the participants' responses. All participants work at a university that uses a one-to-one mentoring model for the dissertation sequence. Each participant has between 30 and 40 doctoral students who are active at any one time; however, each works individually with each student, at the student's pace.

We sent the survey via SurveyMonkey software to all of the current chairs $(N=42)$, using an email link that would ensure anonymity but would also ensure that no chair could respond twice. We sent out two reminders over the course of three weeks to nonrespondents. We received a total of sixteen responses $(n=16 ; 38 \%)$. Within the survey, a qualitative questionnaire, respondents answered two demographic questions (gender and years of experience in online graduate education). Participants then elaborated on their perceptions about the trust constructs of reliability, concern for others, vulnerability, and content-knowledge by answering six open-ended questions. Open-ended questions allowed participants to answer broadly, based upon their unique perceptions of trust, their unique interpretations of the mentor-mentee relationship, and their unique context of working virtually. Again, each chair was a single case, because each chair mentors virtually, from their home environment, and we believe mentors have their own unique ways of conducting their work. Together, our analyses of the participants' responses constituted a multiple-case study of chair perceptions of trust in the mentor-mentee relationship in online doctoral education.

\section{Data Processing and Analysis}

Once the surveys were completed, we downloaded all of the responses into separate Word documents based upon each trust construct. We had one document for the construct of reliability, for example, and all responses related to that construct were included, with a column for gender and years of experience. We did the same for each of the four constructs so that we had four separate documents to code. Next, we had two authors, each with extensive qualitative research experience, separately read and code the responses. One author used a two-pass cycle of coding: (a) active-word coding, such as "I give," "I listen," or "I notice that students often..." and (b) literature-informed etic-issues coding (Saldaña, 2014; Stake, 1995, 2005). These issues included the ideas of students sharing personal information, for example, and of students feeling vulnerable when receiving feedback. The other author incorporated grounded codes (Strauss \& Corbin, 2007), which means that the author put aside previous prejudices, presuppositions, and previous knowledge of the subject area. Instead, the author concentrated on finding new themes in the data not previously represented in the literature.

Next, both coders met to compare ideas, and reduced codes to a list of themes for each trust construct. Interestingly, though both qualitative authors coded from diverse perspectives, we came to quick agreement about the themes drawn from the data. We then shared our coded results with the other two researchers for feedback and input. In the next section, we present these themes, as supported by the data, followed by a discussion section in which we look back to our literature to extend knowledge of the online doctoral mentor-mentee relationship. 


\section{Weaknesses and Limitations}

While we believe that having two of us code and all four of us discuss results increases the reliability and trustworthiness of our interpretations, we acknowledge the inherent weaknesses in our choices, as all four of us work as dissertation chairs in an online environment. It is possible that our interpretations were derived from our own experiences; however, by using data to support our results below, we believe that our interpretations are valid and confirm, rather than disconfirm, many of our own experiences. We also had one coder use grounded codes (as mentioned in the previous section) to assist with the process of being aware and careful with our own preconceived ideas of what participants might mean.

We acknowledge that the boundaries of the case and the small number of participants may be seen as limitations. These purposeful choices indicate that we did not intend to create results that are generalizable to all online schools, nor all online doctoral mentors. Instead, our purpose is to provide enough detail that a reader can discern instances of reference to their own experiences, or what Stake (1995) terms “naturalistic generalization” (p. 85).

\section{Results}

We have organized the results below under each research question. We indicated how many participants answered the questions we designed for each research question. All participants expressed their perceptions that building and maintaining trust was an important part of the online doctoral mentormentee relationship. Yet all chairs had diverse ways of establishing trust, and particularly of helping students to alleviate their own vulnerability, which can be a barrier to establishing trust in the mentormentee relationship.

\section{Q1. How Do Online Dissertation Chairs Define and Establish Trust With Their Students?}

To answer this question, we asked dissertation chairs to provide open-ended definitions of how they perceive and establish trust in the dissertation chair-mentee relationship. Virtual doctoral dissertation chairs with a varied level of experience, ranging from a minimum of 2 years to a maximum of 10 years, provided definitions of trust and gave examples of how they established trust with their students. Fifteen chairs responded to the question about defining trust, while 16 responded to the prompt about how they established trust with their students.

We chose Feedback, Consistency, and Personal Connections as themes around which to organize chair responses. The findings as organized under these themes helped us to create a conceptual framework for dissertation chairs to help lead students to successful completion of doctoral study through the building of trust between mentor and mentee throughout the dissertation journey. Participants defined trust with their students in terms of showing respect for their students through diverse educational pedagogies, mentoring behaviors, and supportive techniques. Chairs who understand that the dissertation is a monumental scholarly undertaking can build trust with their students by explaining that completion requires commitment, many revisions, and can at times be frustrating. Similarly, chairs who emphasize with their students that the dissertation is a grueling process can establish relationships with their mentees based upon honesty and communication.

Feedback. Chairs frequently wrote of the importance of feedback, and how trust can be built through consistent and timely feedback on student writing. Some chairs described feedback as following through on promised responses. Chairs emphasized that meeting expected turnaround times for giving feedback on revisions and keeping student-chair appointments were critical to students being able to depend upon them for help through the dissertation process. Chairs expressed the need to guide students through the academic process without students having to worry if their chair was going to be responsive. 
As one chair expressed, "My student knows that I have his back.” Another chair communicated that when a student encounters a difficult issue, "She knows I will be here to help her sort it out."

Consistency. Participants also frequently emphasized the need for consistency (from the mentor) as a necessary factor in building trust between mentor and mentee. Some chairs defined consistency as establishing a pattern of communication when the chair has a vested interest in the student's progress and success by professionally communicating with students and engaging in conversations based on mutual respect. Other chairs described consistency as efforts by the chair to repeatedly demonstrate how the chair can identify specific areas on which the student should focus and then to help the student find ways to work on those areas, and also to navigate the complexities and challenges of the dissertation journey. One area chairs mentioned was that they often had to help the student create a realistic framework for completion of the dissertation. Chairs mentioned some ways to do this, such as having set office hours, keeping telephone appointments and Skype chat meetings, and responding to student inquiries within set time requirements. Chairs felt that all of these tactics increased students' confidence levels in their mentors' abilities to guide them. Other ways mentioned included sending outreach letters when students were absent from the course room, and being consistent in approach in terms of support. As one chair reported, "I respond to communications as soon as possible; my students know that I am always on their side.”

Personal connection. Several chairs mentioned that they initially try to personalize the academic relationship by taking the time to get to know their students as people, and to learn about students' interests, hobbies, professions, and families. By doing so, these chairs mentioned that they find it easier for students to confide in them later in the process when the students are confronted with a challenge, such as needing a leave of absence. Even chairs who did not mention that getting to know their students was important still mentioned the essential nature of always showing empathy and concern for students' personal experiences that may make the dissertation journey more challenging.

\section{Q2. How Do Online Dissertation Chairs Perceive Student Vulnerability, and Work to Alleviate That Vulnerability?}

We asked dissertation chairs to respond to this question via two open-ended prompts. In the first prompt we asked them to explain how they observed vulnerability in their students. Sixteen chairs responded to this prompt. In the second prompt, we asked chairs to provide examples of ways that they worked to alleviate any perceived vulnerability. Because chair responses to the second part of this question were so diverse, we included a greater number of themes to represent participants more fully. First, vulnerability was described as students' discussion of their academic skills (or lack thereof), and students' sharing of personal information (see Table 1, next page).

We will first discuss how chairs perceived vulnerability, and then we will discuss what chairs do to help alleviate that vulnerability. Following that discussion we will discuss chairs' reported methods of encouraging students. This discussion highlights the variety of ways in which chairs perceive student vulnerability, and the necessarily diverse means of addressing such vulnerability.

Perceptions of vulnerability. Vulnerability was perceived in a variety of different ways by chairs, but we grouped all responses into two themes: (a) students' discussions of their own academic skills and (b) students' sharing of personal information. Chairs indicated that students frequently spoke of various skills needed to complete a dissertation, and they also indicated that many students believed they did not have the requisite skills to finish. Some skills were related to writing abilities, and others to research methods abilities, such as understanding how to design a quantitative study, which statistical method to use, or how to implement qualitative data analysis using current standards on coding. Chairs also indicated that students often lacked the ability to see the dissertation as a process and to understand 
the scope of that process over time. When students discussed their limitations with chairs, chairs perceived this as students being vulnerable.

Table 1 Chair Perceptions of Student Vulnerability

\begin{tabular}{|c|c|c|}
\hline Vulnerability & Theme & Subtheme \\
\hline \multirow[t]{2}{*}{ Perceptions of vulnerability } & $\begin{array}{l}\text { Student discussions of their } \\
\text { academic skills }\end{array}$ & $\begin{array}{ll}\text { - } & \text { Knowledge of skill deficits } \\
\text { - } & \text { Perceptions of power } \\
\text { - } & \text { Student realization of scope } \\
& \text { of dissertation process } \\
\text { - } & \begin{array}{l}\text { Anger/blame at } \\
\text { chair/committee feedback }\end{array} \\
\end{array}$ \\
\hline & $\begin{array}{l}\text { Students' sharing of personal } \\
\text { information }\end{array}$ & $\begin{array}{l}\text { - } \text { Personal experiences } \\
\text { - } \quad \text { Self-sabotaging behaviors }\end{array}$ \\
\hline \multirow{6}{*}{$\begin{array}{l}\text { Diverse ways to alleviate } \\
\text { vulnerability and boost student } \\
\text { self-confidence }\end{array}$} & Recognize student strengths & \\
\hline & Help students focus on future & $\begin{array}{ll}\text { - } & \text { Help student visualize } \\
\text { completed dissertation } \\
\text { - } & \text { Discuss postdoctorate career } \\
\text { possibilities }\end{array}$ \\
\hline & $\begin{array}{l}\text { Point out the positives of } \\
\text { vulnerability }\end{array}$ & $\begin{array}{l}\text { Talking or writing about } \\
\text { personal experiences is a way } \\
\text { of thinking and working } \\
\text { through them }\end{array}$ \\
\hline & Reduce sense of isolation & $\begin{array}{l}\text { - Help students understand the } \\
\text { process }\end{array}$ \\
\hline & $\begin{array}{l}\text { Provide strategies and resources } \\
\text { for skill development }\end{array}$ & $\begin{array}{ll}\text { - } & \text { Academics } \\
\text { - } & \text { Writing } \\
\text { - } & \text { Independent, critical thinking } \\
\end{array}$ \\
\hline & $\begin{array}{l}\text { Helping students become } \\
\text { independent scholars }\end{array}$ & $\begin{array}{l}\text { - } \\
\text { - Help students value revision } \\
\text { critical feedback (and not } \\
\text { take it personally) }\end{array}$ \\
\hline
\end{tabular}

Other chairs perceived vulnerability when their students discussed personal information. Sometimes students discussed personal difficulties, such as illnesses in themselves or family members, deaths of family members, or financial difficulties. Other times students discussed ways in which they sabotaged their own work on the dissertation, or lacked self-confidence in their abilities. One chair wrote that students "often share things like they feel like giving up," or that students "can't make time for their work ... they make excuses for not making progress."

Sometimes students expressed their vulnerability to the chair in defensive behaviors. Chairs noted an obvious power construct in the mentor-mentee relationship, and some students used this as an excuse for their lack of skills or progress. Instead of expressing vulnerability, students would express anger or frustration to the chair. One chair described it this way: "I often feel students are afraid to contact me initially and I assume this involves [feelings of] intimidation and fear." Others expressed that students would take on an attitude of defeat and just ask that the chair to "tell me what to write so I can get this over with.” 
Diverse ways to alleviate vulnerability. Because vulnerability was perceived in a variety of ways, chairs had many suggestions for ways to alleviate vulnerability in students and/or to strengthen student self-confidence. We chose six themes to represent chair responses, which initially seemed like too many, but when we thought about the myriad ways that chairs defined vulnerability, having diverse strategies made more sense to us.

Recognition of student strengths. Chairs mentioned the importance of recognizing student strengths. In an open-access, online institution, this was often difficult because so many students come to doctoral study without requisite skills but are still allowed access. It can be difficult to find and recognize strengths, but chairs emphasized how critical this was in the online environment. For example, if a student lacks skills in writing and problem development but is enthusiastic and takes feedback well, the chair would emphasize to the student how important taking and using feedback is to the entire process.

Helping the student focus on the future. One way that chairs can help alleviate the selfsabotaging behaviors of students who feel vulnerable, or who feel angst that has resulted in a continuing lack of progress, is to help the student understand what life could be like with a completed dissertation. Helping the student to focus on the future possibilities that the degree will allow often could empower students to work through any vulnerabilities that were preventing them from progressing. This visualizing technique included chairs sharing some personal reflections on their own process and how the degree afforded them a broader range of career possibilities than they would have had without the degree. However, since many of our students are already working adults, this type of thinking about the future may just be about reinforcing the work that the students would like to do but cannot do without the doctorate.

Point out the positives of vulnerability. Another way chairs helped students work through vulnerabilities and move toward progress was to emphasize student vulnerabilities as strengths. Sometimes sharing personal information (which can be a vulnerable moment) with another person that you trust can help you work through situations to reach resolution. Students often shared personal struggles with chairs. One chair stated, "We are vulnerable when we share emotions or concerns and I think that is a necessary component of the long term, meaningful relationship between chair and mentee." Other times, students revealed vulnerability in relation to their own skills and abilities needed to complete the dissertation. By acknowledging their strengths and weaknesses (vulnerabilities), the student and chair could then work to help the student develop a plan to improve any deficits. One chair stated, "Selfquestioning is an essential component of being a scholar, and is a trait to encourage, rather than reduce."

Reduce sense of isolation. Sometimes chair strategies to reduce student vulnerability and bolster self-confidence centered on the chair becoming vulnerable by sharing their own experiences in the dissertation process, thereby normalizing the student's experience and helping the student understand that others were going through or had gone through similar challenges. Some participants mentioned this strategy as a way to reduce the student's sense of isolation during the dissertation process, which participants mentioned was more pronounced in an all-online environment in which fellow students and faculty were mostly anonymous throughout their schoolwork. As an example, in a brick-and-mortar environment, faculty and students see each other weekly or monthly, and may meet outside of class to share coffee and discussion about topics and issues. Additionally, in many traditional doctoral programs, students are required to engage in regular scholarly seminars in which they present work in progress, or discuss the process with supportive faculty throughout their schools. Chair assistance to normalize the process is critical in an all-online environment.

Provide strategies and resources for skill development. Chairs also frequently mentioned that a fairly easy way to help students alleviate vulnerability or bolster their self-confidence related to helping them improve the skills and abilities they needed to complete a dissertation, such as providing resources 
and support for writing, grammar, and critical thinking. Chairs mentioned providing documents that they had gathered or created. Chairs also mentioned providing links to websites and creating video tutorials to guide students in various parts of the dissertation-writing process. Chairs also referred students to the writing support center available in the university. Some chairs emphasized the importance of not doing the work for students, but instead provided resources to help students improve their skills and do it themselves.

Help students become independent scholars. While in this prompt and in previous prompts chairs mentioned the importance of feedback and the importance of providing positive reinforcement (including complimenting students when they do something well), several chairs pointed out that perhaps the greater responsibility and challenge was to move students toward becoming independent scholars. One chair wrote the following:

A lot depends on the student, I think. I do try to provide positive feedback wherever possible. I also try to allow the students to succeed on their own, if the student is able to do that. I don't mean that I don't help them, but I do mean that sometimes I sort of pull back and try not to micromanage the dissertation so that the student has more ownership. When the dissertation overcomes a challenge (i.e., review) the student will know that he/she did it, not me. I hope this boosts selfconfidence. However, this only works with some students, as it appears that some students seem to want micro-management.

The challenge, however, was how to help students who took critical feedback personally to learn to take feedback constructively. Some chairs helped students to learn to argue in a scholarly manner in response to negative feedback from a committee member (not the chair). This strategy can help students to take ownership of their work and to build self-confidence as the student progresses through the dissertation process and becomes an independent scholar. Becoming an independent scholar is a critical skill that extends beyond the dissertation process.

\section{Discussion}

The goal of our study was to investigate how dissertation mentors define and establish trust with their doctoral students in an online setting. We sought to identify the mentors' perspectives from a qualitative standpoint in order to help us understand the attributes and skills necessary to build trust in such relationships. We drew upon Harding-Dekam, Hamilton, and Loyd's (2012) suggestion that the responsibility for establishing trust resides with the mentor and added to the scholarship this study of how mentors establish trust. Likewise, we add to Crawford, Randolph, and Yob's (2014) quantitative findings of trust from the student perspective by focusing on the faculty point of view.

In this exploratory study, we subdivided the concept of trust into the four categories of reliance, altruism/concern for others, vulnerability, and content knowledge (Schoorman, Mayer, \& Davis, 2007) and subsequently into two corresponding research questions. First, dissertation chairs from an online university were asked to provide open-ended definitions of trust and give examples of how they establish trust with their students. The findings were organized into three themes, including feedback, consistency, and personal connections. Second, chairs were asked about their perceptions of student vulnerability and how they work to alleviate such feelings. Chairs described vulnerability as students' discussions of their academic skills (or lack thereof) and students' sharing of personal information. To alleviate vulnerability, chairs offered many solutions, including recognizing students' strengths, boosting student selfconfidence, focusing students on the completion of the dissertation, and highlighting the positives of vulnerability. 
Findings from the first research question on how to establish trust indicated the significance of feedback, consistency, and personal connections for faculty members (Crawford, Randolph, \& Yob, 2014; Lerners \& Sitzman, 2006). Given the online environment, chairs stressed the importance of providing timely feedback on student work and following through on promised responses that heightened students' confidence in their mentoring. Consistency was also defined by chairs as providing reliable mentoring techniques to offer support and guidance to students working on the monumental task of completing a dissertation. The importance of creating personal connections with students was also emphasized by chairs, and in particular the process of getting to know students beyond academic conversations. Chairs revealed that students need to be perceived as people who need empathy and concern during the dissertation process in order to achieve academic success (Leners \& Sitzman, 2006).

In response to the second research question about vulnerability, faculty perceptions of student vulnerability included both students' discussion of their academic skills and their sharing of personal information. Chairs expressed that students showed vulnerability by exposing their anxiety about inadequate academic competencies needed to complete the dissertation, such as a lack of writing and research method abilities. Similarly, vulnerability was unveiled when students related their fear of the dissertation as an insurmountable task. Students also disclosed personal difficulties, such as illness or family struggles. Such vulnerabilities could be projected in defensive manners, such as annoyance or dismay at the chair due to the power dynamic in the mentor-mentee relationship. In other words, students blamed their chairs for their own lack of progress.

Chairs were very resourceful in enacting strategies to alleviate all types of student vulnerability. Strategies included recognizing student strengths and pointing to the positives of vulnerability and by offering scholarly resources for students to develop their academic strengths. In addition, chairs coached students to imagine the future by envisioning a finished dissertation and the associated career possibilities. Chairs also worked to reduce students' sense of isolation resulting from attending an online environment by leading them through each step of the dissertation journey. For some chairs, this meant frequent phone calls and quick response to student questions in the course room. For others, this meant frequent reminders of the nature of each milestone and the nature of the dissertation as an iterative process. Still others spoke about the need to help students visualize what comes after the dissertation-a new job, a promotion, or other possibilities, including the potential for the student to conduct future research.

\section{Recommendations for Future Research}

Our suggestions for future research include exploring how trust can be repaired if the mentormentee relationship is disrupted or broken. The process of repairing the relationship could be studied from both the student and faculty perspectives in online universities. Mentors and mentees who have a significant investment in the relationship may differ in their responses to relationship dissatisfaction. In addition, some doctoral mentor-mentee pairings, such as the pairings at this university, are arranged by others and leave little room for change. This type of situation may lead to more active attempts by the mentor and/or the mentee to repair and continue the relationship rather than end it. Erdam and Aytemur (2008) found that negative relationships with mentors were associated with negative attitudes toward academic life, suggesting that maintaining positive relationships with doctoral students is a worthwhile task when mentoring future academicians.

Likewise, an investigation into how university culture influences how trust is built in the mentormentee relationship is warranted (Erdam \& Aytemur, 2008). In a qualitative study of four mentor-mentee pairs, Chan (2008) found that candid discussions about ethnicity and culture were valued by ethnic minority mentees (who were predoctoral students), even if the mentor was not from a minority group. To the extent that ethnicity or cultural background may be masked in the online environment, it would be worth investigating how mentors establish trust when these factors are unknown by the mentor yet still 
important to the mentee. In other words, mentees may benefit from discussions about prejudice and privilege, but the mentor may not initiate such discussions when mentee category memberships are not known.

\section{Conclusion}

Given the rapid rise in enrollment in online doctoral programs (Allen \& Seaman, 2012), establishing trust and alleviating student vulnerability is necessary for successful completion of the dissertation. Our study points to the myriad of techniques online chairs can use to build trust with their doctoral students and reduce student vulnerability to help students finish their doctoral degrees. Implications from these findings not only highlight the skill sets required by faculty to build trust in their mentoring relationships, but also how to limit students' angst about the process.

\section{References}

Allen, I. E., \& Seaman, J. (2012). Changing course: Ten years of tracking online education in the United States, 2013. Babson Survey Research Group.

Burner, K. (2014). From candidate to colleague: Mentoring online doctoral students. The Journal of Online Doctoral Education, 1, 101-111.

Chan, A. W. (2008). Mentoring ethnic minority, pre-doctoral students: An analysis of key mentor practices. Mentoring \& Tutoring: Partnership in Learning, 16(3), 263-277.

Crawford, L. M., Randolph, J. J., \& Yob, I. M. (2014). Theoretical development, factorial validity, and reliability of the Online Graduate Mentoring Scale. Mentoring \& Tutoring: Partnership in Learning, 22(1), 20-37. doi:10.1080/13611267.2014.882603

Darley, J. M., Zanna, M. P., \& Roediger, H. I. (2004). The compleat academic: A career guide (2nd ed.). Washington, DC: American Psychological Association.

Eller, L. S., Lev, E. L., \& Feurer, A. (2014). Key components of an effective mentoring relationship: A qualitative study. Nurse Education Today, 34(5), 815-820. doi.org/10.1016/j.nedt.2013.07.020

Erdem, F., \& Aytemur, J. Ö. (2008). Mentoring—a relationship based on trust: Qualitative research. Public Personnel Management, 37(1), 55-65.

Erwee, R., Albion, P., van Rensburg, H., \& Malan, R. (2011). Dealing with doctoral students: Tips from the trenches. South African Journal of Higher Education, 25(5), 889-901.

de Janasz, S. C., \& Godshalk, V. M. (2013). The role of e-mentoring in protégés’ learning and satisfaction. Group \& Organization Management, 38(6), 743-774. doi:10.1177/1059601113511296

Harding-DeKam, J. L., Hamilton, B., \& Loyd, S. (2012). The hidden curriculum of doctoral advising. NACADA Journal, 32(2), 5-16.

Hunt, K., Brimble, M., \& Freudenberg, B. (2011). Determinants of client-professional relationship quality in the financial planning setting. Australasian Accounting Business \& Finance Journal, 5, 69-99.

Jairam, D., \& Kahl, D. H., Jr. (2012). Navigating the doctoral experience: The role of social support in successful degree completion. International Journal of Doctoral Studies, 7, 311-329. 
Kritsonis, W. A. (2011). Functions of the doctoral dissertation advisor. FOCUS On Colleges, Universities \& Schools, 6, 1-5.

Krot, K., \& Lewicka, D. (2012). The importance of trust in manager-employee relationships. International Journal of Electronic Business Management, 10(3), 224-233.

Leck, J., \& Orser, B. (2013). Fostering trust in mentoring relationships: An exploratory study. Equality, Diversity \& Inclusion, 32(4), 410-425. doi:10.1108/EDI-01-2010-0007

Leners, D. W., \& Sitzman, K. (2006). Graduate student perceptions: Feeling the passion of CARING online. Nursing Education Perspectives, 27(6), 315-319.

Lunsford, L. (2012). Doctoral advising or mentoring? Effects on student outcomes. Mentoring \& Tutoring: Partnership in Learning, 20(2), 251-270. doi: 10.1080/13611267.2012.678974

Melrose, S. (2006). Mentoring online graduate students: Partners in scholarship. Education for Primary Care, 17, 57-62.

Parker, K., Lenhart, A., \& Moore, A. (2011). The digital revolution and higher education: College presidents, public differ on value of online learning. Washington, DC: Pew Internet \& American Life Project (http://pewinternet.org).

Saldaña, J. (2014). The coding manual for qualitative researchers (2nd ed.). Thousand Oaks, CA: Sage.

Schoorman, F. D., Mayer, R. C., \& Davis, J. H. (2007). An integrative model of organizational trust: Past, present, and future. Academy of Management Review, 32(2), 344-354. doi:10.1177/1059601111428449

Stake, R. E. (1995). The art of case study research. Thousand Oaks, CA: Sage.

Stake, R. E. (2005). Multiple case study analysis. New York, NY: Guilford Press.

Stadtlander, L. M., \& Giles, M. J. (2010). Virtual instruction: A qualitative research laboratory Course. Teaching of Psychology, 37(4), 281-286. doi:10.1080/00986283.2010.510971

Strauss, J., \& Corbin, A. (2007). Basics of qualitative research: Techniques and procedures for developing grounded theory (3rd ed.). Thousand Oaks, CA: Sage.

Trinkner, R. (2014). Procedural justice and the advisor-advisee relationship in graduate education. The Journal of Online Doctoral Education, 1, 23-40.

Tzafrir, S. S., \& Dolan, S. L. (2004). Trust Me: A scale for measuring manager-employee trust. Management Research, 2(2), 115-132. doi:10.1108/15365430480000505

Tzafrir, S. S., \& Gur, A. A. (2007). HRM practices and perceived service quality: The role of trust as a mediator. Research \& Practice in Human Resource Management, 15, 1-16.

Williams, S., Sunderman, J., \& Kim, J. (2012). E-mentoring in an online course: Benefits and challenges to e-mentors. International Journal of Evidence Based Coaching \& Mentoring, 10(1), 109-123.

Yob, I., \& Crawford, L. (2012). Conceptual framework for mentoring doctoral students. Higher Learning Research Communications, 2(2), 34-47. 


\section{Appendix-Trust Survey}

\section{Demographics}

1. Please indicate how many years of experience you have had directing online dissertations both at NCU and prior to working at NCU:

2 years or less

$3-5$ years

6-9 years

10 or more years

2. Please indicate your gender (type in your response).

\section{Trust Constructs: Reliability, Concern, Vulnerability, Content Knowledge}

1. Trust is sometimes defined as being able to rely on someone. How and in what ways do you show to your students that they can rely on you?

2. Mentors may exhibit the characteristic of concern for others. Please give an example of how you have demonstrated concern for your mentees.

3. Another characteristic of the trust relationship noted in the literature is that of vulnerability, specifically on the part of the mentee. How and in what ways do you notice your students as being vulnerable (please give examples).

4. Continuing to examine the characteristic of vulnerability, we also ask: How do you try to strengthen students' self-confidence and/or reduce that vulnerability in your students?

5. Lastly, we examine the construct of content knowledge. Content knowledge as a subconstruct of trust is a complicated construct for us as dissertation chairs at NCU. Each of us has a specific area of content knowledge that we were hired for and that we have expertise within. How do you as a graduate school dissertation chair define your content knowledge as it pertains to the work of your students?

6. Further, the construct of content knowledge can be used to mediate trust in the relationship. How and in what ways does your content knowledge influence, improve, or mediate the trust relationship with your mentees? 